\title{
Enhanced nodulation and symbiotic effectiveness of Medicago truncatula when co-inoculated with Pseudomonas fluorescens WSM3457 and Ensifer (Sinorhizobium) medicae WSM419
}

\author{
Sharon Lee Fox • Graham William O'Hara • \\ Lambert Bräu
}

Received: 7 March 2011 / Accepted: 12 August 2011 / Published online: 15 September 2011

(C) The Author(s) 2011. This article is published with open access at Springerlink.com

\begin{abstract}
Aims Low numbers of rhizobia in soil or inoculants delay nodulation and decrease symbiotic legume productivity. This study investigated the effect of coinoculation with a helper bacterium, Pseudomonas fluorescens WSM3457 on the Medicago truncatula Ensifer (Sinorhizobium) medicae WSM419 symbiosis challenged by a low inoculum dose.

Methods In a glasshouse experiment the effect of coinoculation with WSM3457 on the kinetics of nodule initiation and development was assessed 5, 7, 10, 14, 17, 21, and 42 days after inoculation of $M$. truncatula cv. Caliph with $10^{3}$ cells/plant of E. medicae WSM419.

Results Co-inoculated plants had enhanced rate of nodule initiation and development, greater numbers of larger crown nodules, and by day 42 accumulated more $\mathrm{N}$ than plants inoculated with $E$. medicae WSM419 alone. Nodule development was altered by co-inoculation. Approximately $25 \%$ of nodule initials on co-inoculated plants formed in closely associated pairs, young nodules were larger with multiple meristems and developed into cluster-like multi-
\end{abstract}

Responsible Editor: Peter A.H. Bakker.

S. L. Fox $\cdot$ G. W. O’Hara $・$ L. Bräu $(\bowtie)$

Centre for Rhizobium Studies, School of Biological

Sciences and Biotechnology, Murdoch University,

South Street,

Murdoch 6150, Western Australia

e-mail: 1brau@murdoch.edu.au lobed nodules compared to those on WSM419 inoculated plants. Molecular typing showed WSM3457 occupied a significant proportion of root nodules on co-inoculated plants.

Conclusion Co-inoculation with P. fluorescens WSM3457 enhanced symbiotic effectiveness of $M$. truncatula when inoculated with a low inoculum dose of $E$. medicae WSM419.

Keywords PGPR $\cdot$ Rhizobia $\cdot$ Nodulation enhancement $\cdot$ Co-inoculation $\cdot$ Ensifer

(Sinorhizobium) medicae $\cdot$ Medicago truncatula
Abbreviations
PGPR Plant Growth Promoting Rhizobacteria
WSM Western Soil Microbiology
DAI Days After Inoculation

\section{Introduction}

Legumes and their associated nitrogen-fixing bacterial symbionts, the rhizobia, are an integral part of many agricultural systems (Howieson et al. 2007). In addition to being valuable high protein food crops and sources of fodder, and contributing to the sustainable nitrogen economy of soils (Peoples et al. 2009), symbiotic legumes can also improve soil structure and fertility, and assist in controlling weeds, pests and diseases through crop rotations (Howieson 
et al. 2000). The productivity of nitrogen-fixing crop and pasture legumes is often challenged by environmental conditions that are detrimental to the survival of rhizobia in the soil, such as $\mathrm{pH}$, aridity, high temperatures, low clay content, excess of heavy metals and salinity (Brockwell 2001; Peoples et al. 2009; Zhang and Smith 1995). Moreover, when rhizobia inocula are used during pasture or crop establishment, mishandling of the inoculum before sowing, dry sowing, and adverse environmental conditions can contribute to poor survival of inoculant rhizobia on seed and in the soil (Howieson and Ballard 2004; O'Hara 2001). Low numbers of rhizobia in the soil or in inoculants can result in delayed nodulation and an overall loss of legume productivity (Denton et al. 2007).

Plant growth promoting rhizobacteria (PGPR) are soil bacteria which, when grown in association with a host plant, result in stimulation of growth of their host (Vessey 2003). It has been reported PGPR can improve the growth and productivity of a variety of agricultural crops, including canola, wheat and rice (Dobbelaere et al. 2003) and legumes (Bai et al. 2002b; De Leij et al. 2002; Marek-Kozaczuk et al. 2000). Since the 1970's there have been an increasing number of reports of 'helper' PGPR enhancing a variety of legume-rhizobia symbioses (Vessey 2003). The effects of PGPR co-inoculation on legume symbioses include increases in nodule number and/ or nodule weight, and in some cases an enhancement of nitrogen fixation or $\mathrm{N}$ accumulation. A variety of mechanisms have been proposed for the observed responses of symbiotic legumes to PGPR coinoculation including phytohormonal stimulation of root growth (Vessey and Buss 2002), increased production of nod gene products inducing flavonoids by the legume host (Andrade et al. 1998), stimulation of root hair development (Lucas Garcia et al. 2004) and secretion of B vitamins by the PGPR enhancing rhizobial growth in the rhizosphere (Marek-Kozaczuk and Skorupska 2001). Of particular interest to PGPR enhancing nodulation is the production of the phytohormone indole acetic acid (IAA). This plant hormone stimulates root elongation and increased density of both root hairs and lateral roots (Arshad and Frankenberger 1991; Gray and Smith 2005). As roots are the initiation point for nodule formation increased growth could result in more colonisation sites for rhizobia.
Pseudomonas fluorescens WSM3457 (previously reported as Alcaligenes xylosoxidans WSM3457), a gram-negative rhizosphere bacterium isolated in Western Australia, was reported to enhance root mass and nodulation of Trifolium subterraneum (sub clover) when co-inoculated with Rhizobium leguminosarum bv. trifolii WSM409 (Flores-Vargas and O'Hara 2006). We have since used 16s SrRNA sequencing to identify this strain as P. fluorescens (NCBI Genbank database, accession number JF423119). Subsequently it was shown that $P$. fluorescens WSM3457 can increase shoot yields and nodulation scores of Medicago truncatula when used as a co-inoculant with Ensifer (Sinorhizobium) medicae WSM419 (S. Fox, unpublished Honours Thesis, Murdoch University, 2006).

This study was undertaken to investigate the effect of co-inoculation with WSM3457 on the kinetics of nodule initiation and development in M. truncatula when the symbiosis is challenged by a low inoculum dose of rhizobia. In glasshouse experiments legumes are often inoculated with $10^{7}-10^{9}$ root nodule bacteria (Hirsch et al. 2009; Howieson et al. 1995; Tang et al. 2001; Terpolilli et al. 2008). However, when seeds are inoculated prior to sowing in the field, the inoculum density is much lower, in the order of $10^{4}$ cells per gram of seed. M. truncatula and Medicago sativa have both been reported to have limited nodulation when inoculated with less than $5 \mathrm{x}$ $10^{3}$ (Caetano-Anolles and Bauer 1988; Macchiavelli and Brelles-Marino 2004). The use of a rhizobial inoculum containing $10^{3}-10^{4}$ was adopted to place the symbiosis under pressure and to mimic bacterial populations more likely found in field situations (Ballard and Charman 2000).

\section{Materials and methods}

Bacterial strains and growth conditions

P. fluorescens WSM3457 was previously isolated from the roots of annual ryegrass (Lolium rigidum G.) growing in a vineyard in the Swan Valley, Western Australia (Flores-Vargas and O'Hara 2006). E. medicae WSM419 was isolated from nodules of Medicago murex in Sardinia (Howieson and Ewing 1986). Both strains were sourced from the Western Soil Microbiology (WSM) collection held at the Centre for Rhizobium Studies at Murdoch University. 
E. medicae WSM419 was cultured using $1 / 2$ LA medium (Howieson et al. 1988) and WSM3457 was cultured in Nutrient Broth (Difco). For solid media the broth was supplemented with $1.5 \%(\mathrm{w} / \mathrm{v})$ agar. Both strains were grown at $28^{\circ} \mathrm{C}$, E. medicae WSM419 for $72 \mathrm{~h}$ and $P$. fluorescens WSM3457 for $24 \mathrm{~h}$. Broth cultures were grown on an orbital shaker at $200 \mathrm{rev} \mathrm{min}^{-1}$.

Determining indole acetic production

Indole acetic acid production by $P$. fluorescens WSM3457 was quantified using the microtitre plate method described by Sarwar and Kremer (1995). Amounts of IAA produced were expressed as mg IAA equivalents/mg cellular protein (Bio-Rad Laboratories, Inc).

Glasshouse experiment

M. truncatula cv. Caliph was subject to four treatments; 1) plants inoculated with E. medicae WSM419; 2) plants co-inoculated with E. medicae WSM419 and WSM3457; 3) non-inoculated plants with added nitrogen ( $5 \mathrm{ml}$ of $0.5 \mathrm{M} \mathrm{KNO}_{3}$ weekly) and; 4) a non-inoculated control with no nitrogen added.

The pots were arranged in the glasshouse in a block-randomised design, with each block containing four replicates of each treatment. Four replicates (four plants per replicate) from each treatment were harvested at 5, 7, 10, 14, 17, 21 and 42 days after inoculation (DAI).

\section{Surface sterilisation of seed}

Seeds of M. truncatula cv. Caliph were sorted for uniformity and lightly scarified using fine sandpaper. Seeds were surface sterilized by soaking in $70 \%(\mathrm{v} / \mathrm{v})$ ethanol for $1 \mathrm{~min}, 3 \%(\mathrm{v} / \mathrm{v})$ sodium hypochlorite for $3 \mathrm{~min}$ and then rinsed six times in sterile deionised water prior to germination on $1.5 \%(\mathrm{w} / \mathrm{v})$ water agar plates. Plates were wrapped in aluminium foil and left at room temperature for eight $\mathrm{h}$ before being inverted to allow the emerging radical to grow straight, facilitating the transplanting process. Plates were left at room temperature for $24-36 \mathrm{~h}$, before germinated seedlings were transferred into a steam-sterilised mix of river sand and yellow sand (1:1). Plants were grown using the culture system described by (Howieson et al. 1995), where deficiency of $\mathrm{N}$ limits legume growth except where they are effectively nodulated or are supplied with nitrogen (Terpolilli et al. 2008).

\section{Preparation of inoculant cultures}

Cultures of E. medicae WSM419 and the co-inoculant $P$. fluorescens WSM3457 were adjusted to an $\mathrm{OD}_{600 \mathrm{~nm}}$ of 0.5 with $\mathrm{NaCl}(0.89 \% \mathrm{w} / \mathrm{v})$, to achieve approximately $10^{8}$ cells $\mathrm{ml}^{-1}$. These cultures were then diluted with sterile DI water to achieve an inoculum dosage of $10^{3}$ to $10^{4}$ cells $\mathrm{ml}^{-1} .24 \mathrm{~h}$ after the seedlings were transplanted, the soil where seedling was planted was inoculated with $1 \mathrm{ml}$ of the appropriate inoculum. The non-inoculated $\mathrm{N}+$ and $\mathrm{N}$ - control plants received $1 \mathrm{ml}$ of sterile DI water. Miles and Misra plates were used to quantify the concentration of each strain in the inocula (Vincent 1970).

Assessing the timing of nodule initiation and nodule development on M. truncatula

The roots from plants harvested at 5, 7, 10, 14, 17 and 21 DAI were carefully rinsed clean and then fixed in a solution of $100 \%$ ethanol: $7 \%(\mathrm{v} / \mathrm{v})$ acetic acid (1:3) before storing at $4{ }^{\circ} \mathrm{C}$ until required for nodule initial studies (O’Hara et al. 1988).

A modified version of the root staining procedure described by Tang et al. (1990) was used to count nodule initials. Roots were rinsed clean of the fixative solution, before being cleared in $10 \%(\mathrm{w} / \mathrm{v}) \mathrm{KOH}$ at room temperature for $2 \mathrm{~h}$. The roots were rinsed with water and then acidified in $0.25 \mathrm{M} \mathrm{HCl}$ for $5 \mathrm{~min}$. Roots were then stained in $0.1 \%(\mathrm{w} / \mathrm{v})$ Brilliant green for $30 \mathrm{~min}$ and de-stained in water overnight. Nodule initials were distinguished from lateral root initials (Cheng et al. 2002), and were counted under a dissecting microscope at $\mathrm{x} 20$ magnification (Tang et al. 1990).

Assessing the effect of co-inoculation on nodulation at $42 \mathrm{DAI}$

Shoots and roots of plants harvested at 42 DAI were separated at the hypocotyl. Nodules were counted and individual nodules were scored using a modified version of the system described by Howieson and 
Ewing (1989) (Table 1). Briefly, each nodule was scored according to its size and position on the root system. Plant nodule score was calculated by the addition of the individual scores for each nodule on that plant.

The five largest nodules from each replicate were then picked and surfaced sterilised. Briefly, nodules were soaked in $80 \%(\mathrm{v} / \mathrm{v})$ ethanol for $30 \mathrm{~s}$ (45 s for nodules $>5 \mathrm{~mm}$ ), $3 \mathrm{~min}(5 \mathrm{~min}$ for nodules $>5 \mathrm{~mm}$ ) in $4 \%(\mathrm{v} / \mathrm{v})$ sodium hypochlorite and then rinsed 6 times for $30 \mathrm{~s}$ in sterile DI water. Replicate $0.1 \mathrm{ml}$ samples of the final rinse solutions were plated out onto TY agar (casein enzymic hydrolysate $6 \mathrm{~g} / \mathrm{L}$, yeast extract powder $3 \mathrm{~g} / \mathrm{L}$, agar $12 \mathrm{~g} / \mathrm{L}$ ) to confirm surface sterilisation. Nodules were then individually crushed in $100 \mu \mathrm{l}$ of sterile $0.89 \%(\mathrm{w} / \mathrm{v}) \mathrm{NaCl}_{2}$ and the resulting milky solution streaked onto TY, $1 / 2 \mathrm{LA}$ and NA plates, incubated at $28 \mathrm{C}$, and checked daily for growth. WSM419 was identified based on its typical donut morphology (Garau et al. 2005). Bacteria other than WSM419 were picked and streaked onto both TY and NA until pure cultures were obtained. The 16S rRNA gene of three non WSM419 isolates from three different nodules was sequenced and a sequence homology search conducted as described above.

The shoots and roots were then dried for $4 \mathrm{~d}$ at $70^{\circ}$ $\mathrm{C}$ prior to weighing. The shoots of the four plants from each replicate were then pooled and analysed for nitrogen.

PCR and DNA sequencing of nodule isolates

Bacteria isolated from nodules were grown on nutrient agar for $24 \mathrm{~h}$ and then suspended in sterile $0.89 \%(\mathrm{w} / \mathrm{v}) \mathrm{NaCl}$. Cell suspensions were pelleted at $10,000 \times \mathrm{G}$ for $5 \mathrm{~min}$, before the supernatant was

Table 1 Nodule rating system used to evaluate nodulation (adapted from Howieson and Ewing (1989))

\begin{tabular}{|c|c|c|c|}
\hline Size & Weighting & Position of nodule & Weighting \\
\hline $\begin{array}{l}\text { Large cluster } \\
>5 \mathrm{~mm}\end{array}$ & 4 & \multirow{4}{*}{$\begin{array}{l}\text { On upper tap } \\
(0-5 \mathrm{~cm}) \text { or on } \\
\text { lateral roots } \\
\text { within } 1 \mathrm{~cm} \text { of } \\
\text { upper tap }\end{array}$} & \multirow[t]{4}{*}{2} \\
\hline Large $3-5 \mathrm{~mm}$ & 3 & & \\
\hline Medium 1-3 mm & 2 & & \\
\hline \multirow[t]{2}{*}{ Small <1 mm } & 1 & & \\
\hline & & $\begin{array}{l}\text { Nodules } \\
\text { elsewhere } \\
\text { on root system }\end{array}$ & 1 \\
\hline
\end{tabular}

removed and the cells resuspended in sterile $0.89 \%$ (w/v) $\mathrm{NaCl}$ to OD 2 at $600 \mathrm{~nm}$.

Primers used for the amplification of the $16 \mathrm{~S}$ rRNA sequence were FGPS 6 and FGPS 1509 (Normand et al. 1992). The PCR reaction mixture of $25 \mu \mathrm{l}$ contained $1 \mu \mathrm{l}$ of cell suspension, $0.5 \mu \mathrm{l}$ of 5.5U/ $\mu \mathrm{l}$ Taq DNA polymerase (Invitrogen Life Technologies), $0.5 \mu \mathrm{l}$ of each $50 \mu \mathrm{M}$ primer, $5 \mu \mathrm{l}$ of polymerisation buffer containing dNTPs (Fisher Biotech, Australia), $15 \mu \mathrm{l}$ of UltraPure grade water (Fisher Biotech, Australia) and $2.5 \mu \mathrm{l}$ of $17 \mathrm{mM}$ $\mathrm{MgCl}_{2}$ (Promega Corp.). The PCR conditions consisted of an initial denaturation cycle of $94^{\circ} \mathrm{C}$ for $5 \mathrm{~min}$, then 35 cycles of $94^{\circ} \mathrm{C}$ for $30 \mathrm{sec}, 55^{\circ} \mathrm{C}$ for $30 \mathrm{sec}$ and $72^{\circ} \mathrm{C}$ for $30 \mathrm{sec}$, before one final cycle of $72^{\circ} \mathrm{C}$ for $7 \mathrm{~min}$ in a Bio-Rad PCR thermal cycler. PCR products were analysed by electrophoresis on a $1 \%(\mathrm{w} / \mathrm{v})$ agarose gel at $100 \mathrm{~V}$ for $45 \mathrm{~min}$. The gel was stained in a solution of ethidium bromide for $30 \mathrm{~min}$ and bands visualised under UV. PCR products were stored at $-20^{\circ} \mathrm{C}$.

PCR products were purified using a QIAquick ${ }^{\circledR}$ PCR Purification Kit (QIAGEN Pty Ltd) as per the manufacturer's instructions. The purified product was used as DNA template in the sequencing reactions. Sequencing primers used in this study were FGPS 6 and FGPS 1509 (Normand et al. 1992) and the internal primers $800 \mathrm{~F}$, 1,100 F, 520R and 820R (Yanagi and Yamasato 1993). For each primer the following sequencing reaction was prepared: $4 \mu \mathrm{l}$ of purified DNA template, $4 \mu \mathrm{l}$ of Big Dye Terminator (version 3.1), $1 \mu$ l of 3.2 pmole/1 primer and deionised water to make up a final volume of $10 \mu \mathrm{l}$ per reaction.

The reaction mixtures were amplified for 25 cycles at $96^{\circ} \mathrm{C}$ for $10 \mathrm{sec}, 50^{\circ} \mathrm{C}$ for $10 \mathrm{sec}$ and $60^{\circ} \mathrm{C}$ for $4 \mathrm{~min}$. The resulting DNA template was then purified using the ethanol precipitation protocol outlined by Perkin Elmer (protocol P/N 402078: http://www.perkinelmer.com). Nucleotide sequences were determined using the DNA sequencer model ABI 377 and the ABI Prism ${ }^{\circledR}$ BigDye $^{\mathrm{TM}}$ Terminator v3.0 Ready Reaction Cycling Sequencing Kit with Amplitaq ${ }^{\circledR}$ DNA Polymerase, in accordance with the manufacturers instructions, at the Western Australian State Agricultural Biotechnology Centre (SABC).

The sequence data was aligned using the Geneious Pro 5.0 program (Biomatters Ltd). Sequence homology searches were conducted using the NCBI BLAST algorithm (Zhang et al. 2000). 
Statistical analysis

Data were analysed for homogeneity of variance $(\mathrm{P}=0.01)$ and then subjected to analysis of variance using the multivariate general linear model using the Wilks' Lambda model in SPSS 17.0, using a significance level of $\mathrm{P}=0.05$. Significant treatment means were compared using Fisher protected LSD test (SPSS17.0 for Windows (Lead Technology, Inc)).

\section{Results}

Effect of co-inoculation on timing of nodule initiation and development

Co-inoculation of $M$. truncatula with $E$. medicae WSM419 and WSM3457 enhanced the rate of nodule initiation and subsequently, nodule development (Fig. 1). Non-inoculated plants did not develop root nodules.

Nodule initials were evident in roots of inoculated plants at 5 DAI (Fig. 1). By 14 DAI there were significantly more nodule initials on plants coinoculated with E. medicae WSM419 and WSM3457 compared with those inoculated with E. medicae WSM419 alone (significant at $\mathrm{P}=0.032$ ). Subsequently, the rate of nodule initiation in co-inoculated roots decreased, whereas in WSM419 inoculated roots it increased such that there was no significant difference in number of nodule initials between the two inoculated treatments at 17 and 21 DAI.

The rate of nodule development was enhanced by co-inoculation of $M$. truncatula with $E$. medicae WSM419 and P. fluorescens WSM3457. Root nodules were present on the co-inoculated plants at 5 DAI whereas nodules did not emerge on E. medicae WSM419 inoculated plants until day 10 (Fig. 1b). There were significantly more nodules on coinoculated plants at both 7 DAI $(\mathrm{P}=0.002)$ and 10 DAI $(\mathrm{P}=0.045)$. At the final harvest at $42 \mathrm{DAI}$ there were more nodules on co-inoculated plants $(\mathrm{P}=0.019)$ than on plants inoculated with WSM419 alone. A larger proportion of co-inoculated plants had crown nodulation, $68.75 \%$, compared to those inoculated with only rhizobia, $31.2 \%$, which was reflected in the significantly enhanced nodulation scores $(\mathrm{P}=0.002)$ on co-inoculated plants (Table 2).
$\boldsymbol{A}$
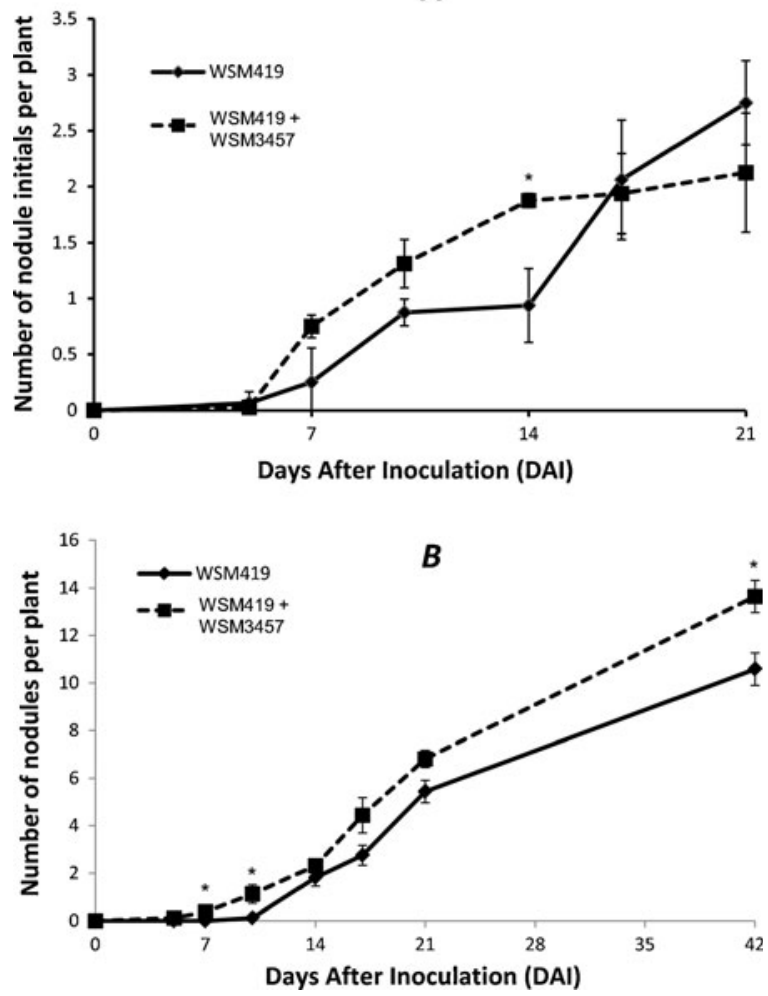

Fig. 1 Number of nodule initials (a) and root nodules (b) on Medicago truncatula cv. Caliph inoculated with Ensifer medicae WSM419 alone or with E. medicae WSM419 and the helper PGPR WSM3457. * Indicates treatment differences that were significant at $\mathrm{P}=0.05$

Nitrogen analysis revealed that at 42 DAI the nitrogen concentrations $(\% \mathrm{~N})$ were similar in shoots of M. truncatula plants from the $\mathrm{N}$ added $(4.01 \% \mathrm{~N})$, WSM419 inoculated $(3.83 \% \mathrm{~N})$, and WSM419 plus WSM3457 co-inoculated $(3.92 \% \mathrm{~N})$ treatments (Table 2). The $\mathrm{N}$ minus control shoots had significantly smaller $\% \mathrm{~N}$ concentrations $(1.51 \% \mathrm{~N})$ than plants from the other three treatment regimes. The total nitrogen accumulated in plant shoots was calculated from the $\% \mathrm{~N}$ and the Dry shoot mass data. Plants in the $\mathrm{N}$ added treatment accumulated significantly more shoot nitrogen than plants from the other three treatments, whereas plants in the $\mathrm{N}$ minus treatment had significantly less total nitrogen in their shoots than the other three treatments. Plants coinoculated with E. medicae WSM419 and WSM3457 accumulated significantly more shoot $\mathrm{N}$ than those inoculated with WSM419 alone ( $\mathrm{P}=0.004)$.

It was observed during the microscopic assessment of nodule initiation that there were differences 
Table 2 Nodule number, nodule score, shoot mass, root mass, $\% \mathrm{~N}$ and Total $\mathrm{N}$ of Medicago truncatula cv. Caliph inoculated with Ensifer medicae WSM419 alone or with E. medicae WSM419 and the helper PGPR WSM3457

\begin{tabular}{|c|c|c|c|c|c|c|}
\hline Treatment & Nodule number & Nodule score & Shoot mass (mg/plant) & Root mass (mg/plant) & $\% \mathrm{~N}$ & Total N (mg/plant) \\
\hline Nitrogen added & & & $177.14 \mathrm{a}$ & $92.68 \mathrm{a}$ & $4.01 \mathrm{a}$ & $7.10 \mathrm{a}$ \\
\hline WSM419 & $10.58 b$ & $16.1 \mathrm{~b}$ & $154.92 b$ & $74.81 \mathrm{a}$ & $3.83 \mathrm{a}$ & $5.88 \mathrm{c}$ \\
\hline WSM419+WSM3457 & $13.645 \mathrm{a}$ & $27.5 \mathrm{a}$ & $167.03 \mathrm{ab}$ & $91.86 \mathrm{a}$ & $3.97 \mathrm{a}$ & $6.61 b$ \\
\hline Uninoculated control & & & $13.49 \mathrm{c}$ & $13.28 \mathrm{~b}$ & $1.51 \mathrm{~b}$ & $0.21 \mathrm{~d}$ \\
\hline
\end{tabular}

between the two inoculated treatments in the morphology of nodule initials and young root nodules. From 7 DAI, up to $25 \%$ of the nodule initials on the co-inoculated plants formed in closely associated pairs (Fig. 2b). This was not observed in plants inoculated with WSM419 alone where nodule initials always occurred as single zones of meristematic cells in the root cortex (Fig. 2a). The young nodules on coinoculated roots at 10 to 21 DAI were often more developed with multiple meristems and were generally larger in size (Fig. 2d) than those on roots inoculated with WSM419 (Fig. 2c). Similarly, at 42 DAI nodules on co-inoculated plants were larger cluster-like multi-lobed nodules (Fig. 3b) compared to those on WSM419 inoculated plants (Fig. 3a).
DNA sequencing of 16S rRNA gene of nodule occupants

There was no bacterial growth on the plates spread with water from the final nodule rinse solution, which shows that the nodule sterilisation process was successful. WSM419 was isolated from all nodules examined. In addition, $40 \%$ of the nodules from the co-inoculated treatment also contained a bacterium that based on visual assessment of colony morphology, colour and colony size was WSM3457. The 16S rRNA sequences from three representative isolates were identical to WSM3457, confirming the co-inoculant bacterium was present in a significant proportion of root nodules sampled from the co-inoculation treatment.
Fig. 2 Seedling roots of Medicago truncatula cv, Caliph after inoculation with with Ensifer medicae WSM419 alone or with $E$. medicae WSM419 and the helper PGPR WSM3457. Nodule initials five days after inoculation with WSM419 (a) and, WSM419 plus WSM3457 (b).

Nodules 17 days after inculation with WSM419 (c) and, WSM419 plus WSM3457 (d). Scale bars $1 \mathrm{~mm}$
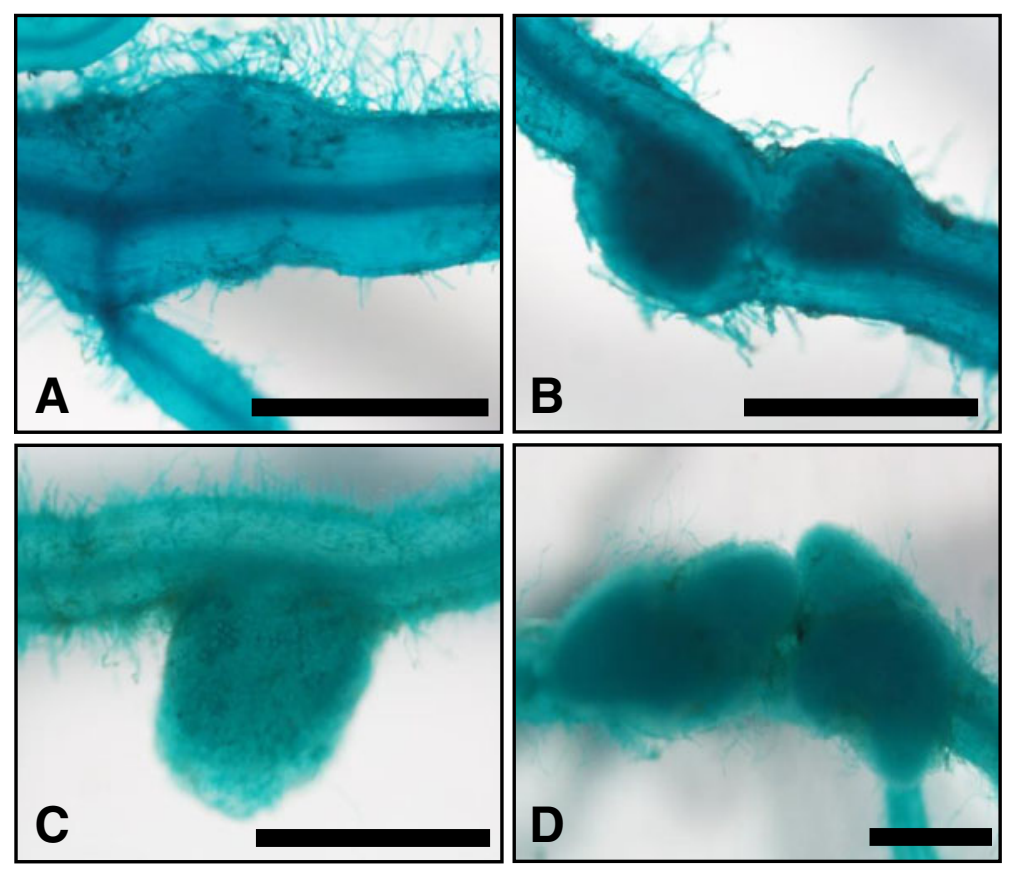


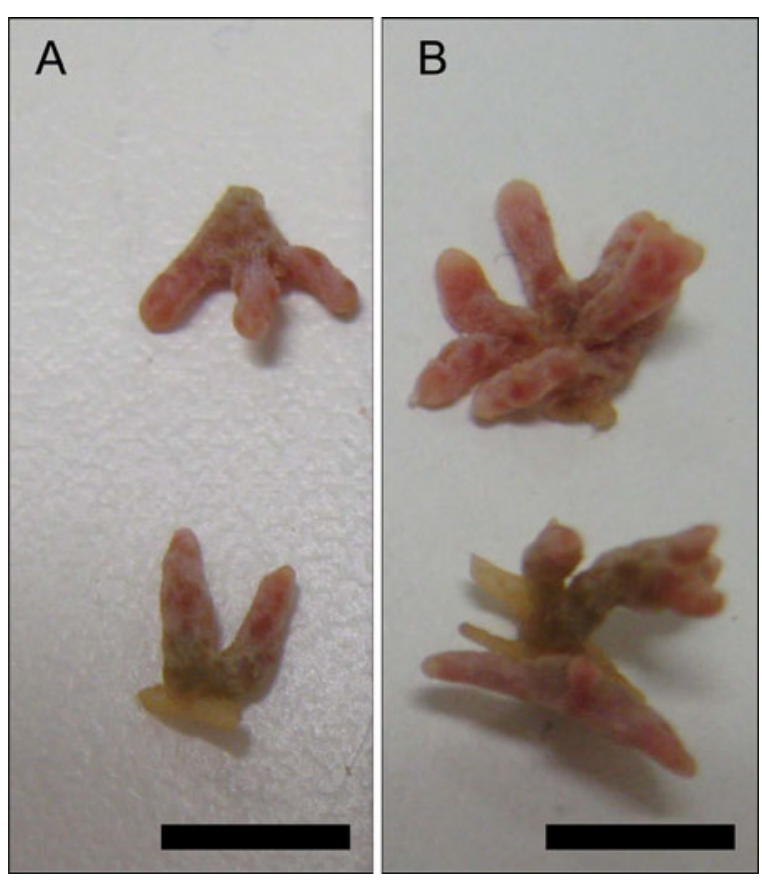

Fig. 3 Representative root nodules on Medicago truncatula cv, Caliph 42 days after inoculation with Ensifer medicae WSM419 alone (a) or with E. medicae WSM419 and the helper PGPR WSM3457 (b). Scale bars $5 \mathrm{~mm}$

\section{IAA production of WSM3457}

WSM3457 produced $0.103 \pm 0.02$ and $0.36 \pm$ $0.07 \mathrm{mg}$ of IAA equivalents per $\mathrm{mg}$ of cellular protein in the - tryptophan and+tryptophan treatments respectively.

\section{Discussion}

Co-inoculation of $M$. truncatula with E. medicae WSM419 and P. fluorescens WSM3457 enhanced the rate of nodule initiation and development resulting in co-inoculated roots forming greater numbers of larger crown nodules earlier than plants inoculated with $E$. medicae WSM419 alone. Co-inoculation also resulted in increased nodule numbers, nodulation scores and total nitrogen accumulation in co-inoculated plants relative to $M$. truncatula inoculated with $6 \times 10^{3} \mathrm{cfu}$ of rhizobia alone. Total dry shoot mass of plants inoculated with WSM419 alone was $85 \%$ of the nitrogen added control plants. By comparison total dry shoot mass of plants inoculated with both WSM419 and WSM3457 was 96\% of the nitrogen added control plants. The increase in both plant mass and nitrogen accumulation in co-inoculated plants represents a marked enhancement of symbiotic effectiveness of $M$. truncatula.

Observations of nodule initials and nodules can be used to differentiate between effects on successful infection and initiation from those on nodule development per se (O'Hara et al. 1988; Tang et al. 1990). Accordingly, the earlier nodule initiation observed on $M$. truncatula co-inoculated with E. medicae WSM419 and P. fluorescens WSM3457 suggests that infection by the rhizobia was enhanced and this conclusion is further supported by the nodule score data. Nodule scores were higher on the co-inoculated plants due to the increase in the proportion of nodules in the root crown and the size of nodules. The relative location of nodules on the root system is a useful index of the time taken for infection, i.e. nodules located on the upper part of the root system are those that were initiated earlier than those on the lower parts of the root system (Bhuvaneswari et al. 1988; Caetano-Anolles et al. 1988). Thus, the increased crown nodulation observed on co-inoculated $M$. truncatula in this study further supports the data demonstrating that root infection occurred earlier with co-inoculation.

The observation that by 7 DAI M. truncatula coinoculated with E. medicae WSM419 and P. fluorescens WSM3457 had nodule initials that were often present in pairs and appeared to have early signs of cluster-like morphology was mirrored by observations that there were often large cluster-like nodules on the co-inoculated plants harvested at 42 DAI. These observations coupled with the data that nodule initiation is enhanced with co-inoculation, raises some interesting questions about the interactions occurring here between WSM3457 and the two symbiotic partners (M. truncatula and WSM419). Namely, does co-inoculation increase the number of $M$. truncatula root hairs infected by E. medicae WSM419? Alternatively, is there no increase in the number of root hairs infected by E. medicae WSM419 but does coinoculation decrease the rate of aborted infection threads? Future work involving a non-destructive root infection assay system, such as the Fahraeus slide method (Fahraeus 1957), will be necessary to answer these questions.

Previous studies have demonstrated that PGPR coinoculation can enhance early nodule initiation and 
development on Phaseolus vulgaris (bean) (Srinivasan et al. 1997), and soybean (Nishijima et al. 1988). Srinivasan et al. (1997) demonstrated that a PGPR isolate, Bacillus megaterium S49, increased the density of root hairs on $P$. vulgaris roots, and concluded that as root hairs are infection sites for rhizobia, that the enhanced early nodulation may be mediated by the increased number of attachment sites. There has also been a recent study demonstrating that a rhizobium strain modified to over produce IAA resulted in increased nodule number on Medicago sp.(Pii et al. 2007). While we have reported here that WSM 3457 produces IAA in vitro, at this stage it is not known whether this strain produces this compound in the rhizosphere of $M$. truncatula. In a previous study, coinoculation of $M$. truncatula with WSM419 and $P$. fluorescens WSM3457 did not alter root physiology compared to inoculation with E. medicae WSM419 alone (S. Fox, unpublished Honours Thesis, Murdoch University, 2006) indicating the enhancement of nodulation reported here is not a result of changes in root hair density.

The 16S rRNA sequencing of the nodule isolates showed that all three isolates examined were the coinoculant $P$. fluorescens WSM3457, which indicates that the co-inoculant is gaining access to root nodules. It is known that approximately $10 \%$ of nodules can occupied by multiple rhizobial strains (Denton et al. 2002; Yates et al. 2008). Likewise there are reports of non-rhizobial species being isolated from legume nodules (Bai et al. 2002a; Mhamdi et al. 2005; Mrabet et al. 2006; Sturz et al. 1997). In one study an Agrobacterium sp., originally isolated from common bean nodules, was tagged with a gus A reporter and then was co-inoculated with rhizobia on soybean. GusA staining confirmed that the Agrobacterium sp. was able to colonise the nodule and that over time seemed to increase in the area colonised (Mhamdi et al. 2005). It is possible that the co-inoculant may concurrently colonise an infected root hair during the infection process and inhabit infection threads. Alternatively WSM3457 may be colonising the outer cortical regions of nodules. Further work is necessary to identify the location of the co-inoculant within the M. truncatula root nodules.

The experimental system used here may prove useful as a tool to study the biological interactions affecting the outcomes of the M. truncatula - rhizobia symbiotic partnership, particularly in light of recent work by Terpolilli et al. (2008) that has demonstrated that $E$. medicae WSM419 is a highly effective partner for this legume species. Moreover, the recently completed E. medicae WSM419 genome (Reeve et al. 2010) provides opportunities toward further understanding of the legume/rhizobia/PGPR interaction reported here. There is now a capacity to assess the effects of co-inoculation on gene expression in WSM419 during the infection process.

The early enhancement of nodule initiation and development reported in this study may offer a significant advantage to the success of nodulation in field grown legumes that are to subject to environmental stressors detrimental to establishment of an effective symbiosis. Helper PGPR, such as P. fluorescens WSM3457, may be useful for enhancing early nodule initiation in legumes to increase the success of rhizobial inoculants under environmental conditions that result in rapid death of the inoculum. Some commercial inoculant products are beginning to emerge that contain plant growth promoting microorganisms as well as rhizobia but these are predominantly focused on phosphate solubilization in the rhizosphere (Leggett et al. 2007). A co-inoculant that enhances nodulation under stressful edaphic conditions, such as the micro-organism described here, could well prove useful in a commercial agricultural setting.

Acknowledgements S. Fox is a recipient of an Australian Postgraduate Award. The authors would like to thank the highly skilled technical assistance of Mrs Regina Carr (Centre for Rhizobium Studies, Murdoch University).

Open Access This article is distributed under the terms of the Creative Commons Attribution Noncommercial License which permits any noncommercial use, distribution, and reproduction in any medium, provided the original author(s) and source are credited.

\section{References}

Andrade G, De Leij FAAM, Lynch JM (1998) Plant mediated interactions between Pseudomonas fluorescens, Rhizobium leguminosarum and arbuscular mycorrhizae on pea. Lett Appl Microbiol 26:311-316

Arshad M, Frankenberger WT (1991) Microbial production of plant hormones. Plant Soil 133:1-8

Bai Y, D’Aoust F, Smith DL, Driscoll BT (2002a) Isolation of plant-growth-promoting Bacillus strains from soybean root nodules. Can J Microbiol 48:230-238

Bai Y, Pan B, Charles TC, Smith DL (2002b) Co-inoculation dose and root zone temperature for plant growth promoting 
rhizobacteria on soybean [Glycine $\max (\mathrm{L}$.) Merr] grown in soil-less media. Soil Biol Biochem 34:1953-1957

Ballard RA, Charman N (2000) Nodulation and growth of pasture legumes with naturalised soil rhizobia 1. Annual Medicago spp. Aust J Exp Agr 40:939-948

Bhuvaneswari TV, Lesniak AP, Bauer WD (1988) Efficiency of nodule initiation in cowpea and soybean. Plant Physiol $86: 1210-1215$

Brockwell J (2001) Sinorhizobium meliloti in Australian soils: population studies of theroot-nodule bacteria for species of Medicago in soils of the Eyre Peninsula, South Australia. Aust J Exp Agr 41:753-762

Caetano-Anolles G, Bauer WD (1988) Enhanced nodule initiation on alfalfa by wild-type Rhizobium meliloti coinoculated with nod gene mutants and other bacteria. Planta 174:385-395

Caetano-Anolles G, Wall LG, De Micheli' MEM, Bauer WD, Favelukes G (1988) Role of motility and chemotaxis in efficiency of nodulation by Rhizobium meliloti. Plant Physiol 86:1228-1235

Cheng Y, Watkin ELJ, O'Hara GW, Howieson JG (2002) Medicago sativa and Medicago murex differ in the nodulation response to soil acidity. Plant Soil 238:3139

De Leij FAAM, Dixon-Hardy JE, Lynch JM (2002) Effects of 2,4, diacetylphloroglucinol- -producing and non-producing strains of Pseudomonas fluoroscens on root development of pea seedlings in three different soil types and its effects on nodulation by Rhizobium. Biol Fert Soils 35:114-121

Denton MD, Coventry DR, Murphy PJ, Howieson JG, Bellotti WD (2002) Competition between inoculant and naturalised Rhizobium leguminosarum bv. trifolii for nodulation of annual clover. Aust J Agr Res 53:1019-1026

Denton MD, Hill CR, Bellotti WD, Coventry DR (2007) Nodulation of Medicago truncatula and Medicago polymorpha in two pastures of contrasting soil $\mathrm{pH}$ and rhizobial populations. Appl Soil Ecol 35:441-448

Dobbelaere S, Vanderleyden J, Okon Y (2003) Plant growthpromoting effects of diazotrophs in the rhizosphere. Crit Rev Plant Sci 22:107-149

Fahraeus G (1957) The infection of clover root hairs by nodule bacteria studied by a simple glass slide technique. J Gen Microbiol 16:374-381

Flores-Vargas R D, O'Hara G 2006 Isolation and characterization of rhizosphere bacteria with potential for biological control of weeds in vineyards. Journal of Applied Microbiology.

Garau G, Reeve W G, Brau L, Deiana P, Yates R J, James D, Tiwari R, O'Hara G W and Howieson J G (2005) The Symbiotic Requirements of Different Medicago Spp. Suggest the Evolution of Sinorhizobium meliloti and S. medicae with Hosts Differentially Adapted to Soil pH. Plant Soil 276:263277

Gray EJ, Smith DL (2005) Intracellular and extracellular PGPR: commonalities and distinctions in the plant-bacterium signaling processes. Soil Biol Biochem 27:395-412

Hirsch S, Kim J, Munoz A, Heckmann A B, Downie J A and Oldroyd G E D 2009 GRAS Proteins Form a DNA Binding Complex to Induce Gene Expression during Nodulation Signaling in Medicago truncatula doi:10.1105/ tpc.108.064501 The Plant Cell Online 21 545-557
Howieson J, Ewing M (1986) Acid tolerance in the Rhizobium meliloti; Medicago symbiosis. Aust J Agr Res 37:55-64

Howieson JG, Ewing MA (1989) Annual species of Medicago differ greatly in their ability to nodulate on acid soils. Aust J Agr Res 40: 843-850

Howieson JG, Ballard R (2004) Optimising the legume symbiosis in stressful and competitive environments within southern Australia- some contemorary thoughts. Soil Biol Biochem 36:1261-1273

Howieson JG, Ewing MA, D’Antuono MF (1988) Selection for acid tolerance in Rhizobium meliloti. Plant Soil 105:179-188

Howieson JG, Loi A, Carr SJ (1995) Biserrula pelecinus L.-a legume pasture species with potential for acid, duplex soils which is nodulated by unique root-nodule bacteria. Aust J Agr Res 46:997-1009

Howieson JG, O'Hara GW, Carr SJ (2000) Changing roles for legumes in Mediterranean agriculture: developments from an Australian perspective. Field Crop Res 65:107-122

Howieson JG, Yates RJ, Foster KJ, Real D, Besier RB (2007) In: Dilworth MJ, James EK, Sprent JI, Newton WE (eds) Prospects for the future use of legumes. In nitrogen-fixing leguminous symbioses. Springer, Netherlands, pp 363-394

Leggett M, Cross J, Hnatowich G, Holloway G (2007) Challenges in commercializing a phosphate-soluabilizing microorganism: Penicillium bilaiae, a case history. In: Velazquez E, Rodriguez-Barrueco C (eds) First international meeting on microbial phosphate solubilization. Springer, Dordrecht, pp 215-222

Lucas Garcia JA, Probanza A, Ramos B, Barriuso J, Gutierrez Manero FJ (2004) Effects of inoculation with plant growth promoting rhizobacteria (PGPRs) and Sinorhizobium fredii on biological nitrogen fixation, nodulation and growth of Glycine max cv. Osumi. Plant Soil 267:143-153

Macchiavelli RE, Brelles-Marino G (2004) Nod factor-treated Medicago truncatularoots and seeds show and increased number of nodules when inoculated with a limiting population of Sinorhizobium meliloti. J Exp Bot 55:2635-2640

Marek-Kozaczuk M, Kopcinska J, Lotocka B, Golinowski W, Skorupska A (2000) Infection of clover by a plant growth promoting Psuedomonas flourescens strain 267 and Rhizobium leguminosarium bv. trifolii studied by mTn5gusA. Antonie Van Leeuwenhoek 78:1-11

Marek-Kozaczuk M, Skorupska A (2001) Production of Bgroup vitamins by plant growth-promoting Pseudomonas fluorescens strain 267 and the importance of vitamins in the colonization and nodulation of red clover. Biol Fert Soils 33:146-151

Mhamdi R, Laguerre G, Tiwari R, Aouani ME (2005) Colonization of Phaseolus vulgaris nodules by Agrobacterium-like strains. Can J Microbiol 51:105

Mrabet M, Mnasri B, Romdhane SB, Laguerre G, Aouani ME, Mhamdi R (2006) Agrobacterium strains isolated from root nodules of common bean specifically reduce nodulation by Rhizobium gallicum. FEMS Microbiol Ecol 56:304-309

Nishijima F, Evans WR, Vesper SJ (1988) Enhanced nodulation of soybean by Bradyrhizobium in the presence of Pseudomonas fluorescens. Plant Soil 111:149-150

Normand P, Cournoyer B, Simonet P, Nazaret S (1992) Analysis of a ribosomal RNA operon in the actinomycete Frankia. Gene 111:119-124 
O'Hara G (2001) Nutritional constraints on root nodule bacteria affecting symbiotic nitrogen fixation: a review. Aust J Exp Agr 41:417-433

O’Hara G, Dilworth MJ, Boonkerd N, Parkpian P (1988) Irondeficiency specifically limits nodule development in peanut inoculated with Bradyrhizobium sp. New Phytol 108:51-57

Peoples M, Brockwell J, Herridge D, Rochester I, Alves B, Urquiaga S, Boddey R, Dakora F, Bhattarai S, Maskey S, Sampet C, Rerkasem B, Khan D, Hauggaard-Nielsen H and Jensen E 2009 The contributions of nitrogen-fixing crop legumes to the productivity of agricultural systems. In Symbiosis. pp 1-17. Springer Netherlands.

Pii Y, Crimi M, Cremonese G, Spena A, Pandolfini T (2007) Auxin and nitric oxide control indeterminate nodule formation. BMC Plant Biol 7:21

Reeve W, Chain P, O’Hara G, Ardley J, Nandesena K, Bräu L, Tiwari R, Malfatti S, Kiss H, Lapidus A, Copeland A, Nolan M, Land M, Hauser L, Chang Y, Ivanova N, Mavromatis K, Markowitz V, Kyrpides N, Gollagher M, Yates R, Dilworth M, Howieson J (2010) Complete genome sequence of the Medicago microsymbiont Ensifer (Sinorhizobium) medicae strain WSM419. Standards in Genomic Sciences 2:77-86

Sawar M, Kremer RJ (1995) Determination of bacterially derived auxins using a microplate method. Lett. Appl. Microbiol. 20: 282-285

Srinivasan M, Petersen DJ, Holl FB (1997) Nodulation of Phaseolus vulgaris by Rhizobium etli in the presence of Bacillus. Can J Microbiol 43:1-8

Sturz AV, Christie BR, Matheson BG, Nowak J (1997) Biodiversity of endophytic bacteria which colonize red clover nodules, roots, stems and foliage and their influence on host growth. Biol Fert Soils 25:13-19
Tang C, Hinsinger P, Drevon JJ, Jaillard B (2001) Phosphorus deficiency impairs early nodule functioning and enhances proton release in roots of Medicago truncatula L. Ann Bot 88:131-138

Tang C, Robson AD, Dilworth MJ (1990) The role of iron in nodulation and nitrogen fixation in Lupinus angustifolius L. New Phytol 114:173-182

Terpolilli JJ, O'Hara GW, Tiwari RP, Dilworth MJ, Howieson JG (2008) The model legume Medicago truncatula A17 is poorly matched for $\mathrm{N}_{2}$ fixation with the sequenced microsymbiont Sinorhizobium meliloti 1021. New Phytol 179:62-66

Vessey JK (2003) Plant growth promoting rhizobacteria as biofertilizers. Plant Soil 255:571-586

Vessey JK, Buss TJ (2002) Bacillus cereus UW85 inoculation effects on growth, nodulation, and $\mathrm{N}$ accumulation in grain legumes - Controlled-environment studies. Can J Plant Sci 82:282-290

Vincent JM (1970) A manual for the practical study of rootnodule bacteria. Blackwell Scientific Publications, UK

Yanagi M, Yamasato K (1993) Phylogenetic analysis of the family Rhizobiaceae and related bacteria by sequencing of the 16S rRNA gene using PCR and DNA sequencer. FEMS Microbiol Lett 107:115-120

Yates RJ, Howieson JG, Reeve WG, Brau L, Speijers J, Nandasena K, Real D, Sezmis E, O'Hara GW (2008) Host-strain mediated selection for an effective nitrogen-fixing symbiosis between Trifolium spp. and Rhizobium leguminosarum biovar trifolii. Soil Biol Biochem 40:822-833

Zhang F, Smith DL (1995) Interorganismal signaling in suboptimum environments: the legume-rhizobia symbiosis. Adv Agron 76:125-161

Zhang Z, Schwartz S, Wagner L, Miller W (2000) A greedy algorithm for aligning DNA sequences. J Comput Biol 7:203-204 